\title{
On the elusive crystal structure of expanded austenite
}

Brink, Bastian; Ståhl, Kenny; Christiansen, Thomas Lundin; Oddershede, Jette; Winther, Grethe; Somers, Marcel A. J.

Published in:

Scripta Materialia

Link to article, DOI:

10.1016/j.scriptamat.2017.01.006

Publication date:

2017

Document Version

Peer reviewed version

Link back to DTU Orbit

Citation (APA):

Brink, B., Ståhl, K., Christiansen, T. L., Oddershede, J., Winther, G., \& Somers, M. A. J. (2017). On the elusive crystal structure of expanded austenite. Scripta Materialia, 131, 59-62.

https://doi.org/10.1016/j.scriptamat.2017.01.006

\section{General rights}

Copyright and moral rights for the publications made accessible in the public portal are retained by the authors and/or other copyright owners and it is a condition of accessing publications that users recognise and abide by the legal requirements associated with these rights.

- Users may download and print one copy of any publication from the public portal for the purpose of private study or research.

- You may not further distribute the material or use it for any profit-making activity or commercial gain

- You may freely distribute the URL identifying the publication in the public portal

If you believe that this document breaches copyright please contact us providing details, and we will remove access to the work immediately and investigate your claim 


\title{
On the elusive crystal structure of expanded austenite
}

\author{
Bastian K. Brink ${ }^{\text {a,c }}$, Kenny Ståhl ${ }^{\text {b }}$, Thomas L. Christiansen ${ }^{\text {a }}$, Jette Oddershede ${ }^{c}$, \\ Grethe Winther ${ }^{a}$ and Marcel A. J. Somers ${ }^{a, *}$ \\ ${ }^{a}$ Department of Mechanical Engineering, Technical University of Denmark, \\ Produktionstorvet B425, DK-2800 Kgs. Lyngby, Denmark \\ ${ }^{\mathrm{b}}$ Department of Chemistry, Technical University of Denmark, Kemitorvet B206, DK- \\ 2800 Kgs. Lyngby, Denmark \\ ${ }^{\mathrm{c}}$ Department of Physics, Technical University of Denmark, Fysikvej B307, DK-2800 \\ Kgs. Lyngby, Denmark \\ *somers@mek.dtu.dk
}

\begin{abstract}
No consistent structural description exists for expanded austenite that accurately accounts for the $h k l$-dependent peak shifts and broadening observed in diffraction experiments. The best available description for homogeneous samples is a face-centered cubic lattice with stacking faults. Here Debye simulations of stacking fault effects were compared to experimental data for macro-stress free homogeneous expanded austenite to show that a faulted structure cannot explain the observed peak displacement anomalies. Instead it is argued that the shifts are the combined result of elastic and plastic anisotropy leading to (strongly) non-linear $h k l$-dependent elastic behavior during composition-induced plastic deformation on synthesis of expanded austenite.
\end{abstract}

Keywords: Expanded austenite, crystal structure, plastic deformation, nitriding, X-ray diffraction $(\mathrm{XRD})$ 
Low temperature surface treatment of austenitic stainless steel, by dissolving nitrogen and/or carbon into the supersaturated solid solution in the austenite lattice, leads to the development of a surface-adjacent zone of so-called expanded austenite. Despite more than three decades of research on expanded austenite [1-3], there is currently no consistent structural description that accurately accounts for the $h \mathrm{kl}$ dependent shifts and broadening observed in diffraction experiments. The most prominent complicating feature of diffractograms of, most notably, nitrogen-stabilized expanded austenite, are the anomalous positions of the 200 (and to a lesser degree 311) reflection(s), which are shifted to lower diffraction angles as compared to an ideal f.c.c. (face-centred cubic) lattice [4] (cf. the upper part of Fig. 1). In addition anisotropic broadening is observed, which is least pronounced for the 111 reflection. The best available description for the anomalous shift of the 200 reflection of an expanded austenite zone grown into an austenitic stainless steel, first proposed by Sun et al. [4], is the effect of elastic anisotropy in the strained expanded austenite surface zone and an enhanced stacking fault density. The presence of stacking faults in expanded austenite has been observed directly with transmission electron microscopy $[5,6]$. The applicability of Sun et al.'s interpretation was convincingly demonstrated for the 111, 200 and 220 peaks of macro-stress free homogeneously nitrided samples of uniform composition, where only the effect of stacking faults needs to be considered $[7,8]$, using Warren's [9] theory to account for the systematic shifts by the presence of stacking faults. For such homogenous samples relatively low stacking fault probabilities were sufficient to explain the relative shifts of the investigated $h k l$.

Apart from the few investigations on homogeneous (gradient free) samples, all other investigations in the literature rely on heterogeneous samples with both a 
composition profile and a macro-stress profile in the depth direction. Fewell \& Priest [10] reviewed ten plausible candidate structures on the basis of synchrotron X-ray diffraction on an expanded austenite zone grown into an austenite substrate. The outcome of their systematic investigation was that no simple structural model is sufficient to describe expanded austenite, and that most likely a combination of elastic anisotropy and faulting is responsible for the observed diffraction patterns of their (strained) sample, i.e. consistent with the original suggestion by Sun et al. [4]. The individual contributions of $h \mathrm{kl}$-dependent lattice strain and stacking fault density to peak shifts have previously been demonstrated for simulated X-ray diffractograms [11].

Concerning the prediction of the $h k l$-dependent peak shifts due to stacking faults, it has been demonstrated that Warren's approach is insufficiently accurate due to unrealistic simplifying assumptions [12]. In Warren's analysis [9] the various profile components comprising a diffraction peak are not equally affected, or may be largely unaffected by stacking faults. Velterop et al. [12] showed convincingly that a weighted summation should be used, but unfortunately, their approach is too complicated to be readily implemented in a Rietveld procedure. Recently, in an effort to obtain a simple (approximate) relation between stacking fault probability, peak shift and peak broadening, avoiding the simplifying assumptions of Warren, Debye simulations of Xray diffractograms were adopted to verify whether the stacking fault model provides an accurate interpretation of the peak shifts for $h k l$ beyond 220 [13]. The main results of these simulations are provided below.

An aspect of the expanded austenite zone that hitherto has not been included in the interpretation of $h k l$-dependent shifts is the occurrence of strong plastic deformation of the lattice as a consequence of a plastic accommodation of the composition-induced volume expansion. Several experimental investigations of the microstructure of 
expanded austenite $[8,14-16]$ as well as modelling of composition and stress profiles [17], have demonstrated that the composition-induced lattice expansion in expanded austenite is largely accommodated by substantial plastic deformation, which develops under a state of (rotationally symmetric) biaxial stress within the plane of the expanded austenite zone. The plastic strain in the direction perpendicular to the surface was calculated to be as high as $16 \%$ [18]. Austenitic stainless steel is strongly elastically anisotropic with an elastically compliant $<100>$ direction while the $<111>$ direction is rigid. Adopting a self-consistent model by Hutchinson [19], Clausen et al. [20] investigated the $h k l$ specific lattice strains parallel to and perpendicular to the load axis for uniaxial tension of f.c.c. polycrystals ( $\mathrm{Al}, \mathrm{Cu}$ and stainless steel) in the plastic region. In this respect it is important to realize that, from a mechanical point of view, the rotationally symmetric biaxial state of compressive stress in expanded austenite deviates by only a hydrostatic stress component from a uniaxial tensile load in the direction perpendicular to the surface. Consequently, provided that free-surface effects can be neglected, the lattice strain and plasticity in expanded austenite in the direction perpendicular to the surface is equivalent to that parallel to a uniaxial tensile direction, as was demonstrated to apply for the lattice rotations in expanded austenite grains [21]. Results similar to those reported by Clausen et al. were obtained with a three dimensional crystal plasticity-based finite element model [22]. The simulated $h k l-$ dependent response was corroborated by in-situ neutron diffraction lattice strain determination $[20,23]$. The results obtained with simulation and in-situ neutron diffraction show a high degree of non-linear behavior in the plastic regime, in particular for the 200 lattice strains (Fig. 2). As will be discussed these results shed a new light on the anomalies observed in X-ray diffractograms of expanded austenite. 
Recently, it was reported on the basis of investigations with nano-indentation $[24,25]$ that the anisotropy of expanded austenite appears to be reversed as compared to the elastic anisotropy of stainless steel. Moreover, comparison of X-ray diffraction lattice strains probed on 111 and 200 reflections suggested that the ratio of the elastic constants of the crystallographic directions $<111>$ and $<200>$ changes with nitrogen content [26]. Also these results could be a consequence of the non-linear behavior of (expanded) austenite in the plastic regime.

The diffracted intensity of randomly oriented identical scattering objects can be calculated as a sum over all the interatomic distances according to the Debye scattering equation [27]. Accordingly, it is possible to calculate the diffracted intensity of any atomic array defined in terms of crystallographic parameters such as atomic composition, coordinates and thermal parameters and explore the effects of crystallographic defects like stacking faults. For the current simulations a modified version of the Debye program developed by Oddershede et al. [28] was applied. All details of the calculations, which yielded shifts consistent with those of Velterop et al. [12], were given in [13].

Simulated peak shifts are compared to synchrotron X-ray diffraction data previously obtained [28] for a homogeneous sample of nitrogen expanded austenite with interstitial occupancy (i.e. the number nitrogen atoms per metal atom), $y_{\mathrm{N}}=0.61$, with reported lattice parameter, $a=4.0022 \AA$ and stacking fault probability, $\alpha_{\mathrm{sf}}=0.0362$ (according to Warren's method) in Fig. 1 (lower part). Here $q_{0}$ refers to the unfaulted position and $q$ to the shifted position where $q=4 \pi \sin \theta / \lambda$ is the magnitude of the scattering vector. Since $q_{0}$ is not known, a combination of lattice parameter, $a$, and 
intrinsic stacking fault probability was optimized to match the experimental 111 and 200 peak positions for nitrogen expanded austenite (giving $a=3.9961 \AA$ and $\alpha_{\mathrm{sf}}=0.06$ ). If the stacking fault model would apply, the peak shifts of higher $h k l$ should align reasonably with the predicted values. Evidently, comparing experimental and simulated peak shifts in Fig.1 such a correspondence may be obtained for 220, 222 and 331, while major discrepancies occur for 311, 400, 420 and (to a lesser extent) 422. Fig. 1 illustrates that deceptively reasonable fits can be obtained when only the first three reflections, i.e. 111, 200 and 220 are considered (even for the Warren model), as in previous investigations $[7,8]$. If only these reflections are available, as is the case on applying $\mathrm{Cr} \mathrm{K}_{\alpha}$ radiation, the intuitive conclusion is that the systematic peak shifts can actually be explained from the presence of stacking faults in the f.c.c. lattice. The current analysis demonstrates that stacking faults alone cannot consistently explain the systematic shifts of the reflections of a macro-stress free homogeneous sample of expanded austenite.

As was demonstrated by self-consistent [20] and finite element [22] crystal plasticity modelling and verified by neutron diffraction data [20,23], the relation between the applied tensile stress and the elastic strain for certain reflections in the elasto-plastic regime is highly non-linear (see Fig. 2). The on-set of non-linearity at the elasto-plastic transition is observed as a deviation from the extrapolated linear behavior from the elastic regime (see dashed lines for 200, 220 and 311 in the experimental graph of Fig. 2).

In particular the 200 reflection shows a strong non-linearity whereas e.g. the 111 reflection appears virtually unaffected. The $<200>$ direction is both elastically the most compliant and plastically the softest direction. Grains with the tensile axis/surface normal along <200> will therefore exhibit the largest elastic strains along this direction 
after plastic deformation due to both elastic and plastic strain partitioning. Grains with $<110>$ along the tensile axis/surface normal exhibit large plastic anisotropy and therefore large contractions along $<200>$ perpendicular to the tensile axis/in the surface plane. These large plastic contractions are partly compensated by a tensile elastic strain in the $\langle 200>$ direction due to interactions with the neighboring grains to maintain connectivity. Consequently, the 200 peak perpendicular to the tensile axis/surface normal experiences a shift towards larger lattice spacings. The peak also becomes broad as the tensile elastic strain only occurs in the fraction of grains with a $<110>$ direction along the tensile axis/surface normal.

The elastic constants applied in X-ray lattice strain analysis, the so-called X-ray elastic constants (XECs), are derived from single crystal data with the assumption of a grain interaction model in the purely elastic regime. As the elastic interactions are affected by the plastic behavior, the XECs for the elastic regime are invalid in the plastic regime. This is obvious from Fig. 2, which shows that different $h k l$-families behave differently in the plastic regime. On transferring the results in Fig. 2 to the case of expanded austenite, it should be noted that the lattice strains in expanded austenite, as determined from 111 and 200 reflections, and the associated (compressive) stresses, as determined from extrapolation of the elastic regime, are about 20-30 times higher than those displayed in Fig. 2 [26] and that the yield strength is enhanced by about a factor 20 as a consequence of solid solution strengthening by dissolved nitrogen [17].

Fig. 2 demonstrates that in particular the elastic lattice strain for the 200 reflection shows a strongly anomalous behavior in the plastic regime. Furthermore, the non-linear behaviors for 200 and 311 deviate from those for the other investigated reflections (111, 220, 331 and 531). Interestingly, the largest anomaly is encountered for the 200 reflection, consistent with the major anomaly in X-ray diffractograms for expanded 
austenite. It appears from Fig. 2 that 111 is relatively insensitive and that for 111 the elastic constants from the elastic regime also apply in the plastic regime. Translated to X-ray diffractograms for expanded austenite under biaxial stress parallel to the surface, the anomaly for 200 (and to a lesser extent for 311) measured in the direction perpendicular to the surface, would imply a shift to lower diffraction angles, while 331 and 220 would be shifted to higher diffraction angles as compared to the unstrained lattice. These latter shifts are not so obvious in the upper part of Fig. 1, which may be explained from the limited stress-strain range investigated in [20] and displayed in Fig. 2.

The consequences of the non-linearity of the XECs for residual stress determination of expanded austenite under biaxial compressive stress parallel to the surface can be discussed as follows. The shift of a 200 reflection towards larger lattice spacings for $\psi=0$ and towards smaller lattice spacings for $\psi=\pi / 2$, leads to a steeper negative slope of the $\sin ^{2} \psi$ plot than in the absence of plastic deformation. Probing the 200 reflection and using the XECs applying for the elastic regime will therefore lead to an overestimation of the residual stress value. As 111 is relatively insensitive (cf. Fig. 2) probing this reflection will lead to a more reliable result. Recent X-ray stress determination attempts on expanded austenite indeed showed systematically higher compressive stress values for lattice strains probed on $\{200\}$ planes as compared to $\{111\}$ [26]. Here discrepancies between lattice strains determined for 200 and 111 were discussed in terms of a change of the elastic compliances as a consequence of the high nitrogen content, such that the ratio $\mathrm{E}_{200} / \mathrm{E}_{111}\left(\mathrm{E}_{h k l}\right.$ being the Young's modulus in the $\langle h k l\rangle$ direction) increases with nitrogen content. It cannot be excluded that nitrogen does affect the elastic properties, but the non-linear behavior in the plastic regime and an increase in the degree of 
plasticity with nitrogen content would be in qualitative agreement with this observation. Tromas et al. [25] concluded on the basis of nano-indentation that a reversal of the elastic anisotropy occurred on development of an expanded austenite zone on the surface of austenitic stainless steel. These results suggest that the elastic properties are influenced by the nitrogen content. Further investigations are required to unravel the combined effect of nitrogen content and non-linear behavior in the plastic regime.

In this respect, two observations in the literature remain to be explained: $i$ ) stressfree expanded austenite of uniform composition also shows anomalous shifts of the 200 reflection, albeit to a relatively low extent as compared to the expanded austenite zone on a thick substrate $[7,8]$ as is also apparent from comparison of expanded austenite on thin foils and thick specimens[4]: ii) the anomalous peak shifts appear to be less pronounced for carbon-stabilized expanded austenite, as it is possible to accurately describe diffractograms with Rietveld refinement without peak shift correction [29].

The synthesis of expanded austenite from thin foils or (fine) powders likely leads to a lower degree of plastic deformation in the expanded austenite zone. In such systems plastic deformation of the relatively thin un-nitrided austenite (with a much lower yield strength than solid solution strengthened expanded austenite) will occur to accommodate the composition-induced volume expansion of expanded austenite. Thereby the extent of plastic deformation in expanded austenite is reduced and thus, smaller anomalous shifts of 200 and 311 reflections will occur. A completely converted foil (or powder) does still contain plastic deformation, either because austenite was deformed prior to conversion to expanded austenite or because plastic deformation is introduced directly in the growing expanded austenite. The occurring macro-stress relief after leveling out composition variations does not (or hardly) lead to a change of the 
anomalies. As the simulations in [20,22] showed, $h k l$-specific lattice strains are retained on removal of the load, implying the presence of micro-strains.

Concerning carbon-stabilized expanded austenite, the composition-induced lattice expansion is considerably smaller than for nitrogen-stabilized expanded austenite, because the solubility of carbon is limited as compared to the solubility of nitrogen [29,30]. Consequently, limited plastic deformation (if at all) occurs during growth of carbon-stabilized expanded austenite. In absence of plastic deformation the anomalies are anticipated not to occur.

Summarizing, in this work Debye simulations of X-ray diffractograms for f.c.c. lattices with intrinsic stacking faults show that stacking faults cannot explain the anomalous peak shifts observed for expanded austenite, but that deceptively accurate descriptions can be obtained for lower $h k l$. Instead, the anomalous peak shifts in X-ray diffraction of expanded austenite are argued to originate from the strong elastic anisotropy of plastically deformed (expanded) austenite. The resulting $h k l$-dependent non-linear behavior in the plastic regime appears consistent with the anomalous shifts in $\mathrm{X}$-ray diffraction patterns for as-nitrided surfaces experiencing an overall macro-stress as well as for homogenous foils/powders experiencing $h k l$-specific micro-stresses. Accordingly, the observed (anomalous) change of X-ray elastic constants with nitrogen content, derived from lattice strain determinations probing 111 and 200 reflections, and assuming equal residual stresses, can be interpreted consistently. Numerical simulations of the actual plastic deformation in polycrystalline f.c.c. lattices under a rotationally symmetric state of biaxial compressive stress in the surface is necessary to fully explain the effect of elastic anisotropy and plastic deformation in expanded austenite. Preferably, such simulations should consider a gradient in the unconstrained volume to 
address $i$ ) the anomalous shifts and line widths in diffraction experiments and $i i$ ) the determination of residual stress by probing the $h k l$-dependent lattice strain in expanded austenite.

This work was supported by the The Danish Council for Independent Research (DFF) under Grant 11-106293.

[1] Z.L. Zhang, T. Bell, Surf. Eng. 1 (1985) 131-136.

[2] T. Christiansen, M.A.J. Somers, Surf. Eng. 21 (2005) 445-455.

[3] H. Dong, Int. Mater. Rev. 55 (2010) 65-98.

[4] Y. Sun, X.Y. Li, T. Bell, J. Mater. Sci. 34 (1999) 4793-4802.

[5] J.C. Jiang, E.I. Meletis, J. Appl. Phys. 88 (2000) 4026-4031.

[6] J.P. Riviére, P. Meheust, J.P. Villain, C. Templier, M. Cahoreau, G. Abrasonis, L. Pranevicius, Surf. Coatings Technol. 158-159 (2002) 99-104.

[7] T. Christiansen, M.A.J. Somers, Scr. Mater. 50 (2004) 35-37.

[8] T. Christiansen, M.A.J. Somers, Metall. Mater. Trans. A 37 (2006) 675-682.

[9] B.E. Warren, in:, X-Ray Diffraction, Massachusetts: Addison-Wesley, 1969, pp. 275-298.

[10] M.P. Fewell, J.M. Priest, Surf. Coatings Technol. 202 (2008) 1802-1815.

[11] T.L. Christiansen, T.S. Hummelshøj, M.A.J. Somers, Surf. Eng. 26 (2010) 242247.

[12] L. Velterop, R. Delhez, T.H. de Keijser, E.J. Mittemeijer, D. Reefman, J. Appl. Crystallogr. 33 (2000) 296-306.

[13] B.K. Brink, PhD Thesis (2015) Technical University of Denmark.

[14] M.P. Fewell, D.R.G. Mitchell, J.M. Priest, K.T. Short, G.A. Collins, Surf. Coatings Technol. 131 (2000) 300-306.

[15] C. Templier, J.C. Stinville, P. Villechaise, P.O. Renault, G. Abrasonis, J.P. Rivière, A. Martinavičius, M. Drouet, Surf. Coatings Technol. 204 (2010) 25512558.

[16] T. Czerwiec, H. He, G. Marcos, T. Thiriet, S. Weber, H. Michel, Plasma Process. Polym. 6 (2009) 401-409.

[17] F.N. Jespersen, J.H. Hattel, M.A.J. Somers, Model. Simul. Mater. Sci. Eng. 24 (2016) 025003.

[18] Ö.C. Kücükyildiz, Private communication 
[19] J.W. Hutchinson, Proc. R. Soc. London. A. Math. Phys. Sci. 319 (1970) 247272.

[20] B. Clausen, T. Lorentzen, T. Leffers, Acta Mater. 46 (1998) 3087-3098.

[21] J.C. Stinville, P. Villechaise, C. Templier, J.P. Rivière, M. Drouet, Acta Mater. 58 (2010) 2814-2821.

[22] D.-F. Li, N.P. O’Dowd, J. Mech. Phys. Solids 59 (2011) 2421-2441.

[23] B. Clausen, T. Lorentzen, M.A.M. Bourke, M.R. Daymond, Mater. Sci. Eng. A 259 (1999) 17-24.

[24] J.C. Stinville, C. Tromas, P. Villechaise, C. Templier, Scr. Mater. 64 (2011) 3740.

[25] C. Tromas, J.C. Stinville, C. Templier, P. Villechaise, Acta Mater. 60 (2012) 1965-1973.

[26] F.A.P. Fernandes, T.L. Christiansen, G. Winther, M.A.J. Somers, Acta Mater. 94 (2015) 271-280.

[27] P. Debye, Ann. Phys. 46 (1915) 809-823.

[28] J. Oddershede, T.L. Christiansen, K. Ståhl, J. Appl. Crystallogr. 41 (2008) 537543.

[29] T.L. Christiansen, K. Ståhl, B.K. Brink, M.A.J. Somers, Steel Res. Int. 87 (2016) 1395-1405.

[30] T.S. Hummelshøj, T.L. Christiansen, M.A.J. Somers, Scr. Mater. 63 (2010) 761763. 
Figure 1: Apparent lattice parameter, $a$, determined from experimental peak positions (upper part) and comparison to simulated peak shifts, expressed as the relative difference in magnitude of the scattering vector $q$, caused by intrinsic stacking faults according to Debye simulations [13] fitted to match the 111 and 200 peak of experimental data for nitrogen expanded austenite [28] (lower part).

Figure 2: Experimental lattice strains for selected $h k l$ as measured with neutron diffraction in the direction parallel to the uniaxial tensile stress applied onto stainless steel. For comparison the predicted lattice strain for 200 is included and represented by the dash-dot line (all experimental data and simulations from [20]). The thin dashed straight lines extrapolate the elastic regime for 200, 220 and 311 reflections to emphasize the non-linearities introduced by plastic deformation. 


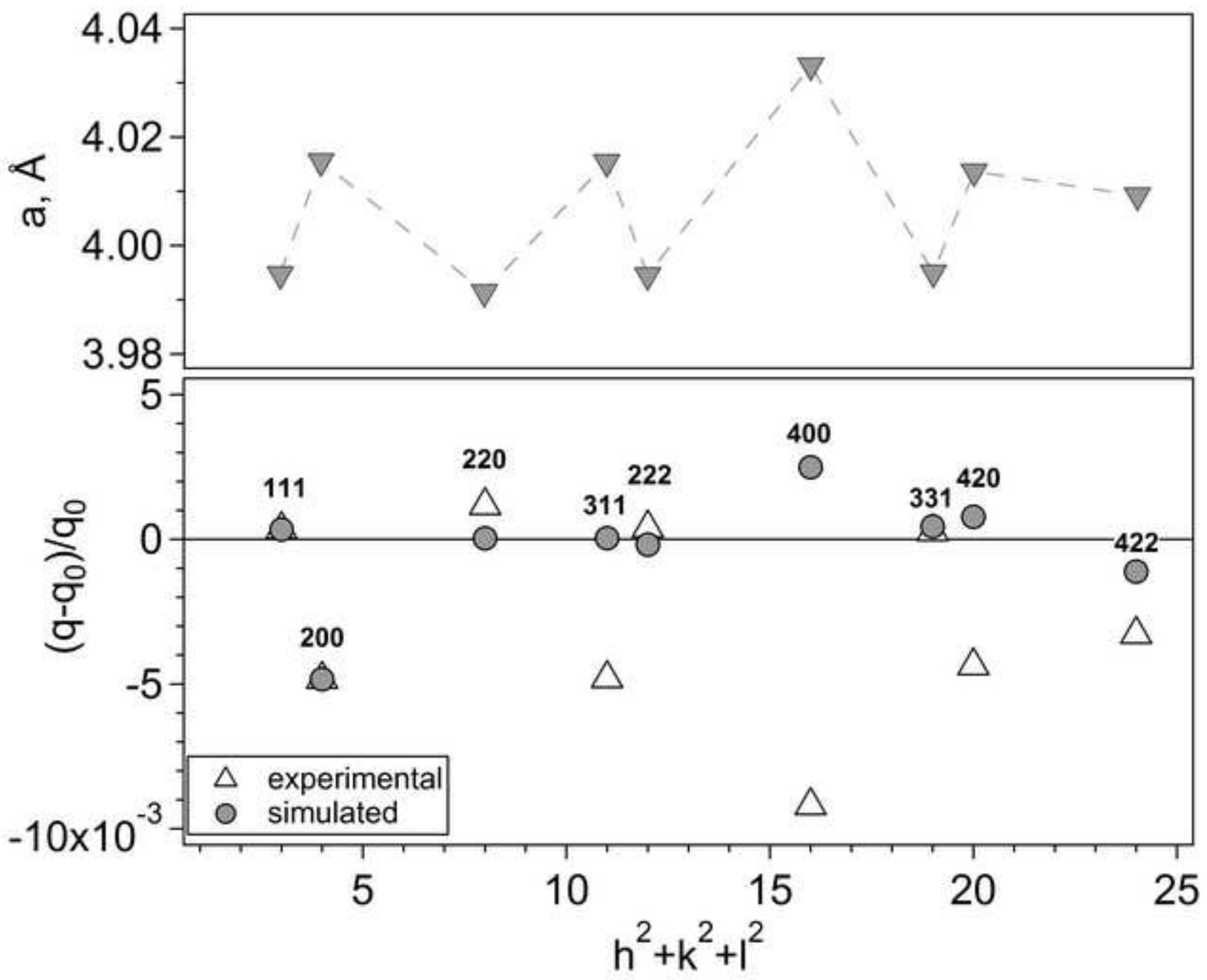




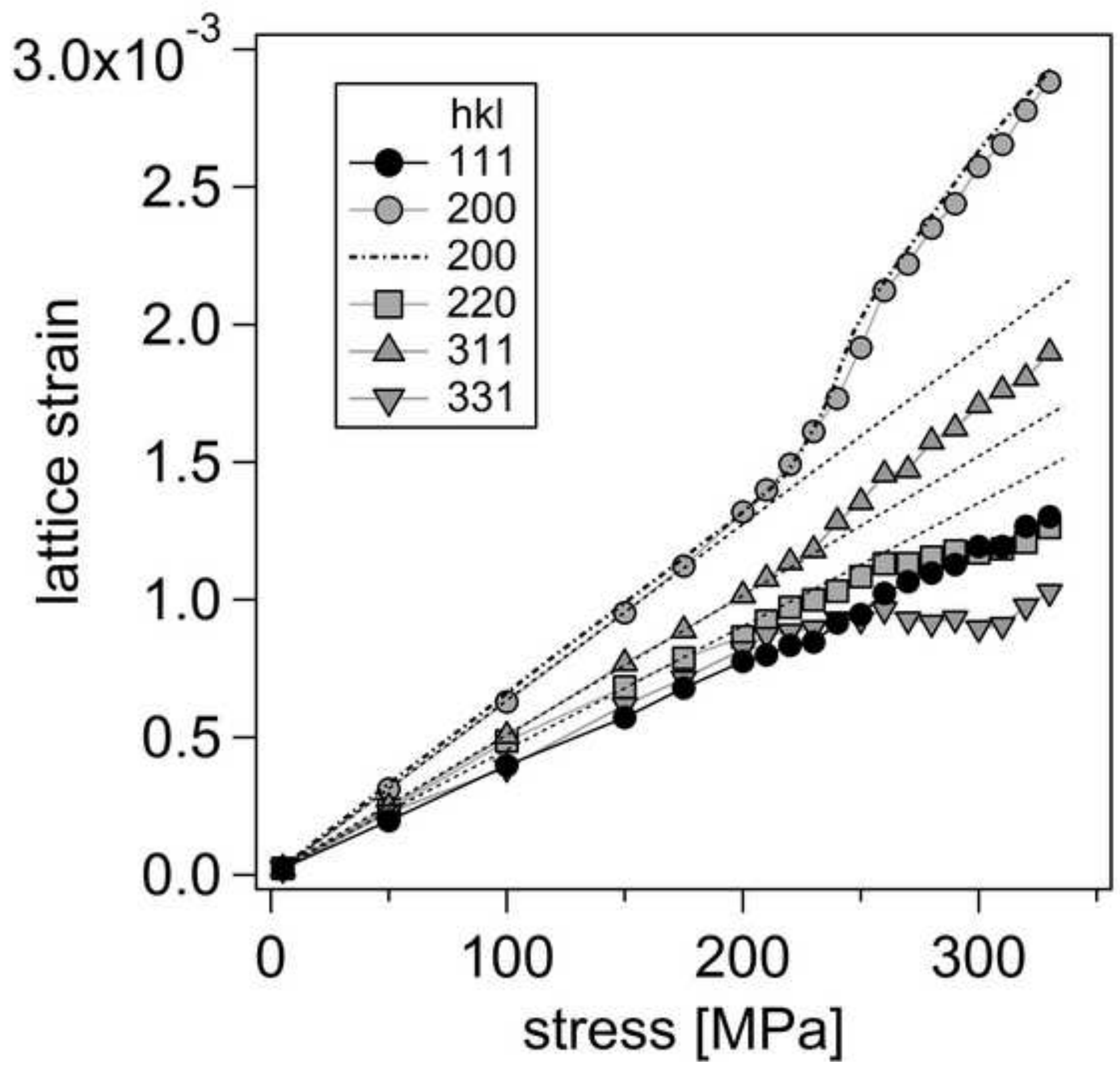

